WellBeing International

WBI Studies Repository

2012

\title{
Confronting Language, Representation, and Belief: A Limited Defense of Mental Continuity
}

\author{
Kristin Andrews \\ York University \\ Ljiljana Radenovic
}

Follow this and additional works at: https://www.wellbeingintlstudiesrepository.org/acwp_asie

Part of the Animal Studies Commons, Comparative Psychology Commons, and the Other Animal Sciences Commons

\section{Recommended Citation}

Andrews, K., \& Radenovic, L. (2012). Confronting Language, Representation, and Belief: A Limited Defense of Mental Continuity. The Oxford Handbook of Comparative Evolutionary Psychology, 39.

This material is brought to you for free and open access by WellBeing International. It has been accepted for inclusion by an authorized administrator of the WBI Studies Repository. For more information, please contact wbisr-info@wellbeingintl.org.

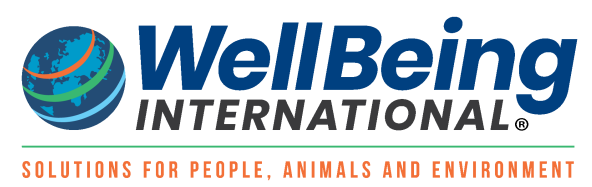


Confronting Language, Representation, and Belief:

A Limited Defense of Mental Continuity

Kristin Andrews and Ljiljana Radenovic

Philosophy, York University, Canada 


\begin{abstract}
According to the mental continuity claim (MCC), human mental faculties are physical and beneficial to human survival, so they must have evolved gradually from ancestral forms and we should expect to see their precursors across species. Materialism of mind coupled with Darwin's evolutionary theory leads directly to such claims and even today arguments for animal mental properties are often presented with the MCC as a premise.
\end{abstract} However, the MCC has been often challenged among contemporary scholars. It is usually argued that only humans use language and that language as such has no precursors in the animal kingdom. Moreover, language is quite often understood as a necessary tool for having representations and forming beliefs. As a consequence, by lacking language animals could not have developed representational systems or beliefs. In response to these worries, we aim to mount a limited defense of the MCC as an empirical hypothesis. First, we will provide a short historical overview of the origins of the MCC and examine some of the motives behind traditional arguments for and against it. Second, we will focus on one particular question, namely whether language as such is necessary for having beliefs. Our goal is to show that there is little reason to think language is necessary for belief. In doing so, we will challenge a view of belief that is widely accepted by those working in animal cognition, namely representational belief, and we will argue that if belief is non-representational, then different research questions and methods are required. We will conclude with an argument that to study the evolution of belief across species, it is essential to begin the study of subjects in their social and ecological environment rather than in contexts that are not ecologically valid along the social and ecological dimensions. Thus, rather than serving as a premise in an argument 
in favor of animal minds, the MCC can only be defended by empirical investigation, but importantly, empirical investigation of the right sort.

Key words: metal continuity claim, evolutionary theory, modern synthesis, language, belief, representation, non-representational belief 


\section{Introduction $(h 1)$}

Generations before Charles Darwin, Aristotle hit upon the notion of mental continuity in The History of Animals:

In the great majority of animals there are traces of psychical qualities or attitudes, which qualities are more markedly differentiated in the case of human beings. For just as we pointed out resemblances in the physical organs, so in a number of animals we observe gentleness or fierceness, mildness or cross temper, courage, or timidity, fear or confidence, high spirit or low cunning, and, with regard to intelligence, something equivalent to sagacity. Some of these qualities in man, as compared with the corresponding qualities in animals, differ only quantitatively: that is to say, a man has more or less of this quality, and an animal has more or less of some other; other qualities in man are represented by analogous and not identical qualities: for instance, just as in man we find knowledge, wisdom, and sagacity, so in certain animals there exists some other natural potentiality akin to these. (Aristotle; http://classics.mit.edu/Aristotle/history_anim.8.viii.html)

Darwin takes things further, arguing that "there is no fundamental difference between man and the higher mammals in their mental faculties" (Darwin, 1871/2010, p. 18). Both Aristotle and Darwin are materialists who accept that the mental faculties are grounded in the physical world. Darwin's addition to Aristotle's picture was, of course, the notion that these mental or psychical qualities were subject to the forces of natural selection. Like other physical properties of animals, the mind is subject to change. Physical as well as mental properties are inherited if they promote the survival of the ancestral members of the species. In other words, physical and behavioral phenotypes are passed on when they benefit the organism (or at least when they don't hinder the organism too badly), which leads to modification by descent. For Darwin there is nothing particularly troublesome or 
problematic about mental continuity over evolutionary time. It is a simple extension of his theory.

The notion that mental properties are material, beneficial, and are distributed across species to varying degrees coupled with evolutionary theory can provide us with the most minimal statement of mental continuity:

Mental Continuity Claim (MCC): Given that human mental faculties are physical and beneficial to human survival, they must have evolved gradually from ancestral forms and we should expect to see their precursors across species.

This way of putting the claim is consistent with many different views of cognitive architecture and the metaphysics of mind. However, the MCC is committed to materialism, according to which all entities are composed entirely of matter, and as such is an explicit rejection of the dualist views associated with many scholars of the Ancient and Medieval period, including some Modern figures such as René Descartes and Nicolas Malebranche. Materialism of mind coupled with Darwin's evolutionary theory leads directly to the continuity claim that we should expect to find ancestral forms of at least some human mental processes in other species. And even today arguments for animal mental properties are often presented with something like the MCC as a premise.

However, there are three potential problems with accepting the MCC as evidence for animal mental faculties. One stems from the lack of clarity surrounding the term "mental". The class of the mental is a motley one; it includes personality traits and beliefs, emotions and reasoning, sagacity and moods, sentience, consciousness, and self- 
consciousness, and it may not be warranted to include all of these properties as subject to modification by descent. For example, not all mental processes are generally beneficial; delusions, negative moods, depression, and false beliefs are all more likely to lead to detrimental effects than beneficial ones.

A second potential problem with the MCC stems from modern advances in evolutionary theory associated with the Modern Synthesis. In the Modern Synthesis, traditional evolutionary theory has been augmented by theories in genetics and molecular biology. One important implication of the Modern Synthesis is a new understanding of physical and mental traits as discrete characteristics of an organism determined by a discrete set of genes. Accordingly, a novel mutation of genes in our ancestral past could have resulted in an entirely new mental trait, one that has no precursors in any other species. In this way MCC could be undermined within the framework of evolutionary theory.

Finally, there is at least one important distinction between humans and other animals: only humans use language. One might suppose that language as a cultural adaptation could serve as a dividing line between humans and other animals when it comes to some aspects of the mental, such as having beliefs, concepts, and rationality. Thus, given both the motley nature of the mental category, and the potential power of language to create new elements of the mental, it is not implausible to suppose that mental continuity has its limits. It could be argued that there is mental continuity when it comes to some aspects of mind such as sentience, consciousness, or even basic reasoning, while there is a wide gap 'in kind' when it comes to other mental faculties such as language, self-consciousness, higher order representations, or a theory of mind. 
In response to these worries, we aim to mount a limited defense of the $\mathrm{MCC}$ as an empirical hypothesis. First, we will provide a short historical overview of the origins of the MCC and examine some of the motives behind traditional arguments for and against it. This isn't an exhaustive exploration in the history of ideas, but rather an introduction into some historical factors that shaped contemporary debates about continuity or discontinuity between animal and human minds.

Second, we will focus on one particular question, namely whether MCC is at least partially undermined by the fact that only humans have language. This is one of the key points of disagreement between primatologists, psychologists, linguists, and philosophers in contemporary literature. In the philosophical literature, the possibility of having a belief without having language has been subjected to a number of challenges. Some philosophers have argued that animals do not have beliefs, and hence cannot be rational, because they lack language (Davidson, 1982; Descartes 1637/2006; Stich, 1979). We will show that these arguments fail, and that there is little reason to think language is necessary for belief. In doing so, we will challenge a view of belief that is widely accepted by those working in animal cognition, namely representational belief, and we argue that if belief is non-representational, then different research questions and methods are required. We will conclude with an argument that to study the evolution of belief across species, it is essential to begin the study of subjects in their social and ecological environment rather than in contexts that are not ecologically valid along the social and ecological dimensions. We believe that this methodological point has broader implications for the study of mental capacities in animals in general, and as such has farreaching implications for our understanding of how to investigate and evaluate the MCC. 
We will conclude that rather than serving as a premise in an argument in favor of animal minds, the MCC can be defended only by empirical investigation, but importantly, empirical investigation of the right sort.

\section{Historical Origins of the Mental Continuity Claim (h1)}

\section{The Great Chain of Being (h2)}

The historical predecessor of the materialist and essentially Darwinian MCC has been the conception of the Great Chain of Being, which dates back at least to neoPlatonists (though its origins can be found in Plato and Aristotle) (Lovejoy, 1936/2009). In Lovejoy's analysis, there are three essential principles guiding the Great Chain of Being: plenitude, continuity, and gradation. The principle of plenitude comes from Plato and it states that a Self-sufficing Being, that is, God, created every type of finite and imperfect entities conceptually possible. From Aristotle we get the principles of continuity and gradation. According to the principle of continuity, if there is a theoretical possibility that there is a third species in nature connecting two existing species, this third species must exist as well because there cannot be any gaps in nature-gaps in nature would indicate that the Creator or God is imperfect, and of course he isn't. Aristotle suggested that according to the principle of gradation we should arrange all animals in an order from the simplest to more complex. In other words, they should be arranged in the scala naturae according to the degree of perfection (for more about the principle of gradation see Wilson, 1980, 260 or Lovejoy, 1936/2009). In neoplatonism and through 
the middle ages, these principles were extended to all things in the universe: inanimate, animate and spiritual (see Lovejoy, 1936/2009, p. 58-60).

While dominant in the medieval period, the idea of continuity and gradation is also vividly present among the $18^{\text {th }}$ century natural historians (such as Charles Bonnet, Carl Linnaeus, and Michel Adanson), who were preoccupied with classification of all species and kinds. However, at this time the thought of the natural historians is still far from the idea of evolution; within their worldview species are fixed. So, when Bonnet expresses his amazement with the similarity between man and orangutan, asking himself "What is one to make of a being which, while it is not properly a man, yet has the stature, the car-riage, the appendages and the strength of man" (Bonnet, 1779, as cited in Anderson, 1976, p.45) he is not motivated by the question of the origins of man, or the common ancestor, but by the ontological assumption that there is an unbreakable continuity in the world, which at the same time makes the world intelligible and justifies any scientific inquiry into its nature.

Mental continuity according to the Great Chain of being accorded some mental capacities to animals (but not to plants) because animals have passions and appetites. However, reason and reasoning abilities remained reserved for humans, and humans conveniently kept both mental and moral superiority over animals and plants despite the principle of continuity ${ }^{1}$. This gap between humans and animals was not seen as a pressing problem given that there was no need to explain how novel, more complex

\footnotetext{
${ }^{1}$ Descartes broke the chain in a much more radical manner by denying that animals feel and have passions. His argument goes as follows: Since only minded creatures have the faculty of sensing, and since only humans can be positively said to have mind given that they are the only creatures with language, animals cannot be minded; rather, they are mere automata. So, according to Descartes only humans have minds. Animals could not have mind to some lesser degree. They could not have it at all. We will come back to Descartes' arguments.
} 
properties evolved from primitive ones. All species were created by God, in descending or ascending order, and each higher species shared some properties with the lower levels, but also included novel properties (Lovejoy, 1936/2009). On the surface the principle of continuity seemed to be satisfied.

With the theory of evolution and publication of Darwin's Origin of Species (1859/2003) the question about the origin and the status of humans became more pressing. While we might see that the old idea of the Great Chain of Being did guide (explicitly or implicitly) the first evolutionary theorists, evolutionary theory introduced an entirely new idea into the old metaphysics: the idea of time and change though time. Evolutionary theory's main point of departure from the Great Chain of Being is the idea that species are not fixed, but that they are changeable and evolve from each other over long periods of time. In the next section we will examine the kinds of implications that this novelty had for the understanding of mental continuity between humans and animals.

\section{The Darwin - Wallace disagreement (h2)}

Darwin's theory of evolution abandoned the linearity and progression present in the Great Chain of Being. According to Darwin, humans could not be the result of progressive modification and they are not some pinnacle of a linear evolutionary process. In the Descent of Man, Darwin (1871) suggested that humans and the other apes could have been the descendants of some common ancestor, such that they both diverged from Old World monkeys. So, the image of the evolution that he suggested was not one of a linear order but rather one of a branching tree. 
Given the non-linear nature of evolution on Darwin's theory, the question of human uniqueness became of central interest, and evolutionary theorists focused on the questions of how humans developed linguistic, cognitive, and moral capacities and how to explain the existence of such capacities within the framework of materialism and natural selection. Alfred Wallace, the co-founder of the principle of natural selection, was unable to cope with such questions from within a materialist worldview, and reverted to Descartes' dualism. For Wallace, evolution could not explain how mental capacities evolved. He argued that somewhere in the distant past human beings were equipped with the mind outside of the process of natural selection. Wallace thought that a superior being (i.e. God) had to be responsible for the development of men or, at least, for men's higher mental powers. ${ }^{2}$ Thus, for Wallace God's intervention established an unbridgeable gap between man and the rest of the animal kingdom, and humans kept the same superiority that they had in the Great Chain of Being. However, the process through which humans gained such superior mental powers was nothing short of a miracle.

Wallace's move is unacceptable to a materialist who is looking for a natural, rather than a supernatural, cause of the phenomena in question. Darwin, of course, had another solution that was in keeping with a materialist world-view. Darwin maintained that the principle of natural selection is sufficient to explain the apparent gap in mental capacities between humans and animals. So far Darwin remained firmly within the bounds of materialism by providing (or at least by attempting to provide) natural causes of mental phenomena. But, Darwin went a little bit further and made one more claim relevant to MCC. He argued that the differences in mental capacities between humans

\footnotetext{
${ }^{2}$ For an extensive overview of the relation between philosophy of mind and evolutionary theory in the $19^{\text {th }}$ century see Weinert, 2009.
} 
and animals are not in kind but only in degree. In other words, it's not only that the human mind is the result of natural processes, along with other capacities of living organisms, but also that we could find capacities of mind to a lesser degree in lower animals.

The question is whether Darwin had to commit himself to the mental continuity claim in order to remain both a materialist and an evolutionist. Many contemporary evolutionary psychologists deny the MCC while still remaining committed to a materialist worldview and the view that the origin of human mind could be explained in natural terms by the processes of natural selection (e.g. Pinker \& Bloom, 1990; Povinelli \& Bering, 2002; Tomasello, 1999). More specifically, many of them would argue that there are some human mental capacities that differ in kind, not only in degree, from those enjoyed by the other animals. It is at this point that we can address why contemporary evolutionary psychologist materialists feel free to deny the MCC while Darwin the materialist could not.

\section{The Modern Synthesis and Mental Discontinuity Claim in Contemporary}

\section{Evolutionary Psychology (h2)}

There are several important events in the history of evolutionary theory and genetics separating Darwin from contemporary evolutionary psychologists. While Darwin's theorizing did not extend to the nature of the discrete units of inheritance- the genes - that are selected for in the process of natural selection, contemporary evolutionary psychologists have at their disposal a theory from molecular biology about the nature of the discrete units. 
During the 1930's Darwin's theory of natural selection was first coupled with genetics in the so-called Modern Synthesis. The Synthesis got its final shape during the 1950 's with developments in molecular biology and the discovery of DNA. According to this view, the processes of natural selection provide an advantage to organisms with adaptive traits, such that organisms with more adaptive traits survive, and the traits themselves are determined by genes consisting of DNA molecules. On this view, the basic unit of selection is not the organism or a trait, but rather a gene. It is the gene that contains the information that is necessary for the occurrence and development of such traits $^{3}$.

Armed with this new picture of evolution and the basic units of selection, contemporary evolutionary psychologists, all committed to materialism and a natural explanation of the occurrence of mental faculties, are not forced to accept MCC (though, of course, they can accept it given additional empirical premises). Borrowing from evolutionary theorists, evolutionary psychologists tend to think of traits as discrete units that are determined by genes and ultimately DNA. Consequently, if they want to argue that there is discontinuity in kind between mental faculties of man and animals they have the necessary space to do so. They are free to account for the occurrence of novel mental faculties by speculating that in the distant past a new gene variation gave rise to an entirely new mental faculty (such as language, theory of mind, etc.). They can then proceed by arguing that the faculty turned out to be advantageous, and accordingly was

\footnotetext{
3 There is a debate among biologists and philosophers of biology to what extent this genocentric view of inheritance is justified (see e.g. Buss, 1987; Frankel, 1989; Oyama, 2000, 2001; Sterelny \& Griffiths 1999; Thompson, 2007). We will leave this question open. Our goal is to examine how evolutionary psychologists took advantage of the notion of discrete unites of inheritance in developing their Mental Discontinuity Thesis. If it turns out that the Modern Synthesis fails it will be on evolutionary psychologists to accommodate or change their views on evolution of human/animal mind accordingly.
} 
selected for in the process of natural selection. Thus, theoretically, mental discontinuity between humans and animals could be explained in natural terms. We do not have to cross the boundaries of materialism, nor do we have to violate the principle of natural selection, in order to do so. Meanwhile, it is clear that Darwin had no options in this matter. Darwin and early Darwinians thought of traits differing continuously from each other and between species. This is why Darwin had to argue that the precursors of mental capacities could be found in lower species. Otherwise, there would be no way to explain their evolution and at the same time remain a materialist. In other words, Darwin had to endorse MCC if he did not want to side with Wallace and Wallace's 'supernatural' explanation of human mental faculties.

While one defense of the MCC is weakened given the Modern Synthesis, it does not undermine the truth of the claim. Rather, it presses the proponents of the MCC to turn to empirical evidence in order to find corroboration for their view. In the last section we will examine how they can go about finding such empirical evidence and what kind of methods would be appropriate for their studies.

So far, we have elaborated on how contemporary evolutionary psychologists got the conceptual framework to argue for discontinuity. Let us now briefly present the mental capacities that are usually proposed to be the points of mental discontinuity between humans and animals. The capacity to learn and use language is often one of the first candidates (Chomsky, 1959 1968; Pinker, 1994). But, there are others too, such as theory of mind (Bermudez, 2003; Tomasello et al. 2005), morality, moral emotions, and moral senses (Hauser, 2000; Kant, 1798; Korsgaard 2006), the ability to reason about unobservables (Povinelli \& Vonk 2004; Vonk \& Povinelli 2006), and symbolic-relational 
reasoning (Penn et al. 2008). Most of the time, though, the argument for discontinuity of one mental capacity (e.g. the ability to feel remorse or theory of mind) relies on the argument that animals do not have language.

Given that the Modern Synthesis does not provide a general criticism of the MCC, we can engage in a limited defense of it by examining particular instantiations of it. The term "mind", as we said earlier, is anything but a term of art. In the next section we will deal with one particular claim about discontinuity between animal and human minds, i.e. the claim that animals do not have the capacity to form beliefs because they do not have language. Careful examination of this claim requires conceptual clarifications of the concepts involved as well as evaluation of conceptual and empirical arguments that are put forth to support (or undermine) it. In a nutshell, our goal will be to show that current arguments about the lack of language and beliefs in animals depend on the acceptance of one version of the representational theory of mind. We present some reasons why that view should be challenged, and conclude that the arguments against animal belief fail.

We then examine one implication of the rejection of a representational theory of mind for research on animal theory of mind. Research on theory of mind implicitly endorses representationalism about belief, according to which for an animal to have a theory of mind it must have the concept of belief as a representational state. We show that if we're right about the nature of belief, there are implications about how to study theory of mind in other species. These implications will be discussed in the penultimate section of the chapter.

\section{Language, Belief, and Mind (h1)}


The claim that animals lack language and hence lack belief involves two potentially contested theoretical concepts: language and belief. In the first case, language can be understood in terms of human language as consisting of a finite vocabulary plus a grammar that allows for the construction of an infinite number of well-formed and meaningful expressions. Chomsky argues that human language can be described along six dimensions (structural principles, physical mechanisms, manner of use, ontogenetic development, phylogenetic development, and integration into a system of cognitive systems), and that so far as we know, animal communication systems lack all of these features (Chomsky, 1980). If the question "do animals have language" is understood to be the question of whether animal communication systems are like human language systems, then Chomsky concludes, it is clear that the differences are so great as to undermine the usefulness of the metaphor. Animals don't use language just as humans don't fly, even though humans can jump off tables and sail through the air for a second or two. If we understand language according to the above constraints, Chomsky concludes, no species other than humans has language.

The most widely accepted model of belief stems from the account of belief/desire psychology discussed by the Scottish philosopher David Hume (1739-40/1978). On the contemporary rendering of this view, belief is defined as an attitude toward some propositional content that takes the content to be true. Belief is one among many other attitudes, including desire, hope, and wonder, and each of these attitudes have a different relationship to its content. Belief is a cognitive attitude in that there is a direction of fit from world to mind. Beliefs are meant to represent actual states of affairs, as contrasted with conative attitudes like desire, in which there is a fit from mind to world. 
Human reasoning is explained by citing the logical nature of our propositional attitudes, and here belief plays a central role. Our beliefs fit together in ways that preserve logical inference, so beliefs connect with one another and with other attitudes to lead to new attitudes. On this picture, beliefs also connect with conative attitudes like desire to lead to action. Thus, belief is taken to be necessary for both practical rationality (i.e. rationality in action) and theoretical rationality (i.e. rationality in the reasonrespecting nature of the flow of thoughts).

Philosophers who are interested in the question of animal minds are very often interested in the possibility of animal belief. This is certainly true of Descartes. In the Meditations, Descartes argued that animals don't have mental lives because they don't talk:

For it is rather remarkable that there are no men so dull and so stupid (excluding not even the insane), that they are incapable of arranging various words together and of composing from them a discourse by means of which they might make their thoughts understood; and that, on the other hand, there is no other animal at all, however perfect and pedigreed it may be, that does the like. This does not happen because they lack the organs, for one sees that magpies and parrots can utter words just as we can, and yet they cannot speak as we do, that is to say, by testifying to the fact that they are thinking about what they are saying; on the other hand, men born deaf and dumb, who are deprived just as much as or more than, beasts of the organs that aid others in speaking, are wont to invent for themselves various signs by means of which they make themselves understood to those who, being with them on a regular basis, have the time to learn their language. And this attests not merely to the fact that the beasts have less reason than men but that they have none at all. For it is obvious it does not need much to know how to speak; and since we notice as much inequality among animals of the same species as among men, and that some are easier to train than others, it is unbelievable that a monkey or a parrot that is the most perfect of its species would not equal in this respect one of the most stupid children or at least a child with a disordered brain, if their soul were not of a nature entirely different from our own. (Descartes, 1637/2000, p. 72) 
While few would take as extreme a view about animal mental life as Descartes did, there are those who defend the more limited claim that language is necessary for belief (Davidson, 1982; Dennett, 1996; Stich, 1979). The updated arguments against animal belief are rather more sophisticated than Descartes', and usually take one of two forms. One kind of argument against animal beliefs is based on the notion that because beliefs are attitudes toward content, we cannot make sense of animal beliefs without making sense of the kind of content they might have. That is, if we cannot say what animals believe it doesn't make sense to think that they believe. The other kind of argument rests on the worry that without language there is no representational vehicle for belief. Beliefs as representation must be represented in some medium, and the only available medium is linguistic. Let us examine both kinds of arguments in turn.

\section{Belief Content without Language $(h 2)$}

Some have claimed that animals do not have beliefs, because a belief is something that can be given specifiable content; beliefs are about something under a particular description. Without language, animals cannot give their own beliefs content, and we cannot designate the content in our human languages, because we have no way of knowing what the content might be. The worry is that we don't know what concepts an animal might have, or how the animal might see the world. If neither animals nor humans can specify the content of animal beliefs, then it is not clear in what sense animals have beliefs.

This worry was first developed, and addressed, by D. M. Armstrong (1973). Armstrong asks us to consider Fido the dog, who just observed his master burying a 
meaty bone in the backyard. The problem, as seen by Armstrong, is that we cannot conclude that "Fido believes there is a meaty bone buried in the yard" because Fido does not have the concept of meaty or bone or yard. In order to have the concept bone, it seems, one also needs to have the concepts skeleton, joint and so forth. In order for Fido to have the concept bone, he would need to know, for example, something about the relation between the skeleton and the muscles of a vertebrate, and their function in animal locomotion. To have the concept bone, one needs to know things about bones, and this requires more concepts.

Armstrong attempts to solve this problem by appealing to the distinction between de re and de dicto belief attributions. A de re belief attribution is an attribution of content without description; it points toward the object of the belief without considering how the believer might conceptualize the belief. A de dicto belief attribution, on the other hand, is the attribution of belief under a particular description; it presents the belief in terms that the believer would agree with. For example, Lois Lane does not believe de dicto that Clark Kent can fly, but she does believe de re that Clark Kent [that guy] can fly.

Though Armstrong thinks that we can never know the belief of Fido de dicto, we can characterize his belief $d e$ re. That is, though we cannot correctly pick out the way Fido is representing the proposition "There is a meaty bone buried in the yard," we know that his belief is directed intentionally towards the meaty bone in the yard; we know that he believes that "[that thing] is [there]". Regardless of how Fido actually represents the meaty bone, when discussing his belief we can refer to this object of Fido's thought as "meaty bone in the yard." We can say "Fido believes there is a meaty bone buried in the 
yard" because, though he does not have the same concept of meaty bone as we do, his belief is still directed intentionally toward the bone.

In his argument against animal belief, Stephen Stich rejects Armstrong's response to the problem by noting the logical feature of the opacity of propositional attitudes (Stich, 1978). It doesn't preserve truth to make substitutions of equivalents within propositional attitudes for humans, so it won't work with animals either. To illustrate, let's return to the Lois Lane example. While it is true that Lois believes that Clark Kent can't fly, and it is true that Clark Kent is the same person as Superman, since Lois doesn't know that the two men are identical, we cannot infer from these two facts anything about her Superman beliefs. Stich argues that we are making just this kind of inference when we ascribe content to an animal's belief, and hence we are making a logical error.

The key premise of Stich's argument against animal belief is the claim that we can never come to understand the kinds of concepts animals might have. Stich defends this claim by showing why Fido doesn't have a bone concept:

He [Fido] may be able to recognize bones tolerably well, provided they are typical examples and presented under conditions that are not too outlandish. But this is hardly enough to establish that he has the concept of a bone or any beliefs or desires about bones. For Fido does not, it seems safe to assume, have any beliefs about the origins and general anatomical function of bones. Nor would he recognize or exhibit any interest in chewing atypical bones-the bones of the middle ear, for example, or the collar bone of a blue whale. Worse yet, Fido does not know the difference between real bones and a variety of actual or imaginable ersatz bones (made of realistic looking plastic, perhaps, and partially covered with textured soy protein suitably flavoured) (Stich, 1978, 18). 
Thus, Stich claims, we are unable to specify the content of an animal's purported belief. Because it is useful to attribute beliefs and desires to animals in order to predict their behavior, animals might have beliefs in the sense that it is useful for humans to attribute beliefs to animals in order to predict their behavior. But this holds for chessplaying computers and automata as well. Just because it is useful to talk about animals as if they have beliefs, that isn't enough to show that they do in fact have beliefs. To show that animals actually have beliefs, it must also be shown that the animals' beliefs have specifiable content. According to Stich, since the content of animals' beliefs can't be specified, it doesn't make sense to say that animals have any beliefs.

One problem with Stich's argument is that the criteria Stich sets out - the knowledge of origins and function, and the ability to distinguish actual from artificial exemplars - are rather odd. Acceptance of these criteria would entail that we don't really have many of the concepts we think we have. Take, for example, the case of a child who is able to identify chicken bones on her supper plate. Perhaps she understands that the bone she broke in her leg is like the chicken bones, but she doesn't really understand the function or origin of bones. Using Stich's criteria, she doesn't have the concept bone. But surely, if she uses the word 'bone' and if she can identify bones as bones, we wouldn't deny that the child has a bone concept. One need not be an expert to have a concept. You can imagine that physicians have a more robust concept of bone than you do, but this doesn't mean that it is improper to say that you have a bone concept. If your doctor were to attribute to you the belief that you broke a bone in your leg, there is no 
practical problem about specifying the content of your belief, even though the doctor's bone concept is different from yours.

Another problem with Stich's argument comes from his pessimism about our ability to understand animal concepts. Stich worries that no empirical investigation will be able to demonstrate the kinds of concepts an animal might have. He appeals again to Fido in making his case. Suppose that Fido, though pretty good at recognizing your garden-variety dog-bone sort of bone, is lousy at recognizing exotic bones that are either very big or very small or not very tasty. And Fido is easily fooled by the soy-coated ersatz bones. We could study Fido's bone-recognizing mechanism by determining what sorts of objects are sorted as bones by Fido, but Stich asserts:

[T] he internal organization of the belief store [of Fido] is as different as you please from the internal organizations of our own belief store. That is, there may be entities--organisms or automata--for which models can be constructed that fit the [folk psychological] pattern ... although the internal organisation of the model's 'belief store' is radically different from the internal organisation of the belief store in models for familiar people (Stich, 1979, 26).

However, there is a host of evidence and argument that flies in the face of Stich's worry, and psychologists have had some success in uncovering the ways in which animals conceptualize the world. A striking example comes from Irene Pepperberg's work with the African Grey parrot Alex, who was trained to sort objects using what might be considered metaconcepts - concepts that categorize other concepts. Alex was able to sort objects according to color, shape, and matter, and he was able to sort sets of objects according to number. Even more impressively, Alex could report which feature makes two objects similar or different. For example, when presented with a red block 
and a red key, Alex would respond to the question "What's same?" by uttering "color." He could also report similarities and differences in shape and matter (Pepperberg, 1999; Chapter 16, this volume). These studies indicate that Alex had a color concept, a concept of shape, and a concept of matter.

As a general principle about how to study animal concepts, Colin Allen proposes the following:

An organism $O$ may reasonably be attributed a concept of X (e.g. TREE) whenever:

i. $O$ systematically discriminates some $X$ s from some non- $X$ s; and

ii. $O$ is capable of detecting some of its own discrimination errors between $X \mathrm{~s}$ and non- $X \mathrm{~s}$; and

iii. $\quad O$ is capable of learning to better discriminate $X$ s from non- $X \mathrm{~s}$ as a consequence of its capacity" (Allen, 1999, p. 37).

For example, if a chimpanzee infant is able to discriminate some nuts from stones, but occasionally makes mistakes and then learns from her mistakes and improves her discrimination abilities, then, Allen would say, we can attribute to the chimpanzee infant the concept of nut.

Another general methodological principle for studying concepts in animals is to use the same methods that are used to study concepts in human infants (Bermúdez, 2003; Gómez, 2005; Hauser et al., 1996; Hauser \& Carey, 1998). Developmental psychologists study infant concepts by using a preferential looking time paradigm, also known as the habituation-dishabituation paradigm (Baillargeon \& DeVos, 1991; Spelke, 1991). In these experiments an infant is repeatedly shown a stimulus until habituated to it, as indicated by a lack of interest in the stimulus. The infant is then shown a new stimulus that differs from the original in some subtle way. If the infant shows a renewed interest in the display, researchers conclude that the infant notices the difference. When the 
difference in stimulus display is a conceptual one, the concept is then attributed to the infant.

This method has been used to study primate concepts; for example, the number concept was studied in rhesus monkeys (Hauser et al., 1996) and cotton-top tamarins (Uller, 1997). The researchers tested the monkeys' ability to keep track of the number of objects that were placed behind a barrier. They found that, like human infants, the monkeys look longer at impossible outcomes. For example, in one test condition the rhesus monkeys were shown two eggplants serially placed behind a screen, and then the screen was lifted showing only one eggplant. The monkeys looked longer at the one eggplant than they did when shown the expected two eggplants, suggesting that they represent the eggplants as distinct sortals.

In addition to these few examples, there is a host of research on concepts and categorizations in different species, using a number of different methodologies, and investigating both abstract and concrete concepts (see Lazareva \& Wasserman 2008 for a review). This research flies in the face of Stich's claim that "nothing we could discover would enable us to attribute content to an animal's belief". There are things we can discover through empirical research, and the more evidence we have, the better we can ascribe content to animals' beliefs.

\section{Representational Vehicle (h2)}

A related worry about belief and language is based on the idea that beliefs need to be represented in some medium, and language is the only possible medium in which to 
represent belief. This worry is associated with representationalism, the most widely accepted account of belief.

For example, those who subscribe to the language of thought hypotheses, there is a necessary connection between belief and language. However, the connection is not so strong as to entail that nonverbal animals don't think. Fodor, for example, believes that animals both think and have a language of thought (Fodor, 1975). It is only the external language that they lack. So a commitment to the language of thought hypothesis would not lead to the conclusion that animals do not think. However, many find Fodor's arguments unconvincing and remain committed to the notion that an external language is needed for belief (Dennett, 1996; Hutto 2008). What Fodor doesn't provide is an error theory, or an explanation of why, if animals think in the language of thought, they do not demonstrate an external language. If Fodor were right, there must be some impediment shared by all nonhuman animal species that have language of thought and no external language.

Regardless of one's take on the language of thought, what representationalists about belief share is the view that belief is a propositional attitude that has a world to mind direction of fit and a reason-respecting flow. For representationalists, beliefs are mental symbols that have the same content as the proposition expressed by the belief. Accordingly, belief is a representational state that shares with sentences the semantic properties of truth, meaning, and reference. Fodor's language of thought is one way of formulating representationalism about belief, but there are others (e.g. Dretske, 1988; Millikan, 1986). 
The argument against animal belief from the representationalist perspective can be stated like this: Beliefs are propositional attitudes, and propositional attitudes are semantically evaluable (true or false, satisfied or not satisfied), have causal powers such that they interact with one another and with the world, and that they are linked together in sensible generalizations that are more-or-less true. Beliefs are also systematic (i.e. the ability to believe that Jack loves Jill entails the ability to believe that Jill loves Jack) and productive (new beliefs can be continually constructed). The only representational vehicle that allows for all of these features is language. Because animals lack language, they lack the requirements for belief.

This argument makes two assumptions. One is that there are no possible nonlinguistic representational systems that permit semantic evaluability, systematicity, and productivity. The second assumption is that belief is representational. We think that both the assumption that language is the only possible representational vehicle and the assumption that belief must be representational are suspect. We will address these assumptions in turn.

The claim that language is the only representational vehicle that explains the features of belief is based on an appeal to ignorance, and arguments that are based on nonexistence claims are always suspect, and for good reason. Other representational systems may be postulated or discovered that would be able to account for these features of belief. Indeed, it has been proposed that representational belief can be understood in terms of maps instead of propositions.

It has been argued that both thought and the rational inference between thoughts can be supported by map views of representation (Braddon-Mitchell \& Jackson, 1996; 
Camp, 2007; Lewis, 1994; Rescorla, 2009). According to map views, mental maps take the place of mental sentences and beliefs are maps "by which we steer" (Ramsey, 1931, cited in Lewis, 1994, 422). A map, like an image, provides a lot of information in virtue of its organization, and cannot be divided up into a set of semantically meaningful smallest parts. In this way, maps are like words, not sentences. One letter out of the word "Toronto" has no meaning, just as the isolated section of a roadmap of North America that contains the dot and the word "Toronto" loses its meaning. Prose, on the other hand, does have a minimum representational unit that maps lack, namely words.

Maps are systematic and productive. Maps have resources that can be rearranged (e.g. if the map can say "Minneapolis is north of Toronto" it could also say "Toronto is north of Minneapolis"), and since those resources can be rearranged in a potentially infinite number of different maps they can be used to express new beliefs.

One worry about map systems is that they don't appear to share all of the expressive power of language. For example, language supports valid deduction because it has the formal elements of propositional logic. If maps lack the logical connectives, then there is no sense in which maps can support rational thought, or explain the reasonrespecting flow of beliefs. Elisabeth Camp (2007) thinks that this concern can be addressed to some extent by maps, and she presents a model of maps that includes negation, disjunction, the conditional, and tense. She concludes that maps have fewer expressive limitations than one might suppose, though she is pessimistic that maps can account for the full expressive power of language. For example, she is unsure how a map view of representation could account for the attribution of beliefs, or for the representation of universally quantified claims. 
While there are some worries about how a map might be able to model all of the logical features available in sentential representational systems, given that work in this area is at a preliminary stage, it is difficult to draw any conclusions about the extent to which a map model of cognition can account for the different kinds of cognition. Camp suggests that humans have both cartographic and sentential systems. Animals, on the other hand, have only cartographic systems. This hybrid approach to the issue is one possibility, but it may be that with more time and with sophisticated modeling tools, maps may be able to account for the full extent of human expression. We remain agnostic on this issue, however. The current state of the research on the map view is sufficient to undermine the strong claim that language is necessary for having belief based on the worry about representational vehicle.

Even if it turns out that map views of belief are severely limited in their expressive power, we remain unmoved, because the bigger concern we have with the argument based on representational vehicle comes from the assumption that belief is representational. This notion, which is widely accepted, is closely associated with the information-processing model of cognition, according to which cognition consists of information being represented, inputted, operated on, and then outputted in terms of behaviors or new beliefs (e.g. Cummins, 1996; Dretske, 1988; Fodor, 1975; Millikan 1984).

Representational accounts of belief do help to elucidate the syntactic nature of thought, but they don't help to explain the semantic nature of beliefs. Sentential systems, in particular, enjoy plausibility given the assumption that language has meaning unproblematically; it is that assumption that drives the argument that by making mental 
states language-like we also solve problems of meaning. But that assumption is false; the nature of the meaning of sentences remains an open area of investigation, so it does not solve any problems to identify belief with sentences (see Speaks 2010 for a discussion).. It merely pushes the question of meaning aside for the time being.

In addition, the representational accounts of belief do perhaps too well when it comes to syntax. Humans, unlike logical systems, make errors, act from biases, and fail to recognize the possible inferences that follow from their sets of beliefs. Thus sentential representational systems also owe an error theory as to why we are not perfect reasoners.

The worries about representationalism also stem from a concern that the term "belief" is a folk concept that will not match onto any physical state or process (Churchland, 1981; Davidson, 1984; Dennett, 1991; Stich, 1983). The representationalists aim to ground belief in a physical state or process, and think that our commonsense understanding of belief must be vindicated by scientific psychology. Those who think that current work in scientific psychology and neuroscience will fail to find a physical basis for belief fall into two camps: the eliminativists and the nonrepresentationalists about belief. Eliminativists argue that the folk concept of belief will one day be discarded in favor of scientifically respectable talk about cognition. This view is based on the promise of future neuroscience and modeling as a means for describing the architecture of the mind in ways that will better help us in our central goals when it comes to belief attribution, namely predicting and explaining behavior.

The non-representationalists of belief are skeptical that future science will either find that there is something physical in common with all the things we refer to when we talk about belief, or that future science will provide us with a framework that we will find 
more useful in our interactions with other people. Because the arguments against animal beliefs are based on a representationalist view of the mind, and there is reason to reject that view, we think it is worth the effort to explore in some detail these nonrepresentational views of mind, and from there go on to examine the methodological implications of accepting a non-representational view of mind.

\section{Nonrepresentational Belief ( $h 2)$}

Whereas the dominant view of belief in the cognitive sciences is representationalism, there are other theories about the nature of belief that deviate from the accepted view. For example, some contemporary research in artificial intelligence and robotics has eschewed the dominant representationalist model of cognition, with interesting results (e.g. Brooks, 1991). Some cognitive scientists and psychologists who accept a connectionist or dynamical approach to modeling cognition also argue that the human mind, and hence belief, is nonrepresentational (Thelen \& Smith, 1994). In philosophy, too, there has been a growing interest in the power of nonrepresentational models of cognition (Clark \& Toribio; Thompson, 2007; Van Gelder, 1995). What nonrepresentationalist views share is a rejection of the view that belief is a symbolic entity, and that thinking is a form of information processing. For nonrepresentationalists, belief can be understood as knowing how rather than knowing that.

We will discuss two different ways philosophers have developed nonrepresentational accounts of belief: dispositionalism and enactive/embodied cognition. On both these views, language is not necessary for belief, and so the content arguments discussed in the previous section do not have any purchase. 


\section{Dispositional belief $(h 3)$}

Whereas the term "disposition" is often associated with behaviorism, the contemporary work on dispositional belief parts ways from behaviorism, and so current dispositionalism is not subject to the criticisms of the behaviorist views. While dispositionalism about belief has been formulated in a number of ways, we will here present two formulations of this idea, one more radical than the other, in order to show the ways in which dispositionalism can be seen as distinct from representationalism.

Ruth Barcon Marcus presents a dispositional account of belief as follows:

$\mathrm{x}$ believes that $\mathrm{S}$ just in case under certain agent-centered circumstances including x's desires and needs as well as external circumstances, $\mathrm{x}$ is disposed to act as if S, that actual or non-actual state of affairs, obtains" (Marcus, 1990, p. 133).

On this account, rather than a belief consisting of the relationship between an attitude and a proposition, believing is a relationship between a subject and a possible state of affairs. Here you see Marcus moving in the direction suggested by Armstrong, such that beliefs are related to their content without needing to be under a particular description, since states of affairs are merely ordered structures of actual objects, properties, and their relations. And note that by talking about dispositions, Marcus does not appeal to any nonphysical entity, since dispositions rely on the microstructure of the entity that has them. But she also does not appeal to representational states. The disposition is not a representation of the belief that it is related to, as the disposition is only part of the belief. The external circumstances are the other necessary aspect of the belief. 
Marcus points to a number of benefits of this model of belief. For one, it is available to non-language users, such as young children and animals. Thus, it avoids the problem the language-centered views of belief have when it comes to the ontogeny of belief development in human children. How children come to have belief is left mysterious on those views, but Marcus is able to account for the development of belief alongside the development of behavioral dispositions. Marcus also suggests that her view better accounts for the fact that others are sometimes in a better position to know what we believe than we are ourselves, and that others can help a believer to more accurately describe her belief by providing a new vocabulary. It is also consistent with the existence of unconscious beliefs (which seem puzzling on a language centered view), and it offers a more natural account of rationality based on the coherence of action, rather than on the consistency of sentences believed. That is, her view avoids another puzzle for the representationalist, namely the empirical fact that humans are not perfectly rational and that beliefs are not closed under logical consequence relations. Rather, on Marcus' dispositionalist view, an agent is rational if her behaviors are coherent; e.g. it is irrational to assert love for a person and yet subject that person to violence.

While Marcus' view is suggestive, it leaves unexamined one of the big challenges for dispositionalism, namely how the behaviors hang together in order to form a single disposition that would be associated with a particular belief. This issue is addressed by another contemporary advocate of dispositional belief, Eric Schwitzgebel. On Schwitzgebel's view, belief is described as follows:

To believe that $\mathrm{P}$, on the view I am proposing, is nothing more than to match to an appropriate degree and in appropriate respects the dispositional stereotype for 
believing that $\mathrm{P}$. What respects and degrees of match are to count as 'appropriate' will vary contextually and so must be left to the ascriber's judgment (Schwitzgebel, 2002, 253).

The account is dispositional because it treats believing as being disposed to do and experience things, but it is also phenomenal because the dispositional stereotype includes emotions and other phenomenal states as well as behaviors. Thus, Schwitzgebel's account of dispositional belief offers a clear break from the behaviorist whose goal was to show that all mental state talk can be reduced to non-mental state talk.

The dispositional stereotype for a belief is a cluster of dispositional properties we are apt to associate with that belief. Thus, belief ascriptions are true or false at a social level of analysis, but may not map onto anything at the physical level. Rather, a belief is more like a personality trait in that it is a stable and habitual pattern of response, and it can differ from person to person. While the personality trait of being hot-tempered can be associated with the stereotype of responding angrily to minor provocations, being slow in cooling off after a fight, feeling and expressing frustration quickly, the belief that there is beer in the fridge can be associated with the stereotype of saying things like, "I've got beer", offering beer to guests, feeling surprise when opening the fridge and finding no beer, etc.

Also, like personality traits, there are a number of different properties associated with a belief stereotype, and no explicit association between the disposition and the belief. People can disagree to some extent what the cluster consists of, yet still share the same belief, just as we can disagree about the cluster associated with concepts such as "chair", yet still be able to share the concept. These considerations allow us to make sense of degrees of belief, or what Schwitzgebel calls "in-between believing" 
(Schwitzgebel, 2001). If a person responds in such a way so as to show many properties of a dispositional stereotype, but not all of them, the ascriber can examine whether the deviation from the stereotype is excused due to the circumstance. If the deviation is not fully excused, if it is seen by the ascriber as an important deviation that makes us hesitate to ascribe the belief, if it makes the ascription less apt, then we might say the individual has the belief to some degree. Schwitzgebel thinks this is a benefit of his theory, because it accounts for real-world cases in which we don't know whether to say that someone has a belief or not. For example, take the case of the implicit racist, who honestly asserts that she thinks race has nothing to do with intelligence, but yet associates black faces with ignorance and white faces with understanding. This person doesn't fully believe the antiracist claim she asserts; she may want to believe it, but her socialization doesn't allow her to fully embrace it. Another example Schwitzgebel asks us to consider is Geraldine's stated belief that all Spanish nouns ending in 'a' are feminine, despite her also asserting that words ending in 'ista' can be either feminine or masculine. When we ask whether she really believes what she says, when her utterances are inconsistent with one another and her behaviors have her using the Spanish language correctly, there is, it seems, nothing left to say in addition to what we already know. Does Geraldine really believe that all Spanish nouns ending in 'a' are feminine? Kind of.

Schwitzgebel's dispositionalism accounts for the continuous nature of belief, something that representationalism about belief cannot do. He writes, Unlike at least some representational approaches to belief, the dispositional account of belief does not leave it as an open question whether, once their dispositional structure is fully characterized, Ellen [who kind of believes her son smokes pot] or Geraldine really have the belief or not. There is no internal chalkboard on which the belief might be written in the language of thought, no warehouse in which it might be stored, despite its inconsistent "manifestations." 
Once all the relevant dispositions have been made clear, the case is closed" (Schwitzgebel, 2002, p. 261-262).

Because for the dispositionalist, beliefs just are patterns of response, there is no deeper question about the content of Geraldine's belief once you have the relevant information about her behavior and phenomenal states. Anyone who wants further information about the cause of Geraldine's behavior is really interested in a different level of explanation (e.g. a neuroscientific explanation).

Given dispositionalism about belief, the question of whether Fido believes there is a meaty bone buried in the backyard is easily answered. What are the dog's dispositions that make up his belief? They might be digging up the bone when hungry for it, surprise if the digging does not bring up the bone, salivation in anticipation of eating the meaty bone, and so forth. But knowing what those dispositions are can only come from empirical evidence about dog behavior; the stereotypes for a belief will certainly differ across species, just as they differ across cultures. But remember that no one of these dispositions is necessary for having the belief, and the belief is not written on the body in any way. Rather, on dispositionalism, the belief is an emergent property of the physical system given its microstructure.

One objection to dispositionalism about belief as it relates to animal belief would be the concern that it solidifies anthropomorphic attributions, i.e. it attributes a property to an animal that can only be held by a human. That is, one might argue that whether or not a response is described as having a belief or not depends on its coherence to a dispositional stereotype, which is something that is constructed by the observers. 
This criticism is better leveled at a third non-representational account of belief, interpretationism, according to which an entity has a belief if it can be interpreted as so having (Davidson, 1984; Dennett, 1991,). On interpretationist views, beliefs are analyzed as relational properties between multiple systems (e.g. people who can observe patterns of behavior) and individuals interpreted as having beliefs. However, according to dispositionalism, beliefs are analyzed as properties of the system that has beliefs; they are dispositional states. The stereotypes help us organize those dispositions into categories we find useful for predicting and explaining behavior, but the dispositions are real features of the system. In order to uncover the actual dispositions of animals, empirical investigation will be required. Dispositionalism is consistent with the possibility that there are commonplace false attributions; the uninformed observer of an animal who makes a false attribution may do so based on, perhaps, a human belief stereotype rather than the dog belief stereotype.

Dispositionalism about belief is non-representational, habitual, and takes beliefs to be patterns of behavioral and affective responses to particular triggers. Thus, for the dispositionalist, belief is essentially a situated phenomenon, and in this sense it shares with the embodied approach to cognition a commitment to analyzing the organism in its own context.

\section{Embodied belief $(h 3)$}

Another way of understanding non-representationalism about belief comes from the research programs associated with embodied and enactive cognition. On such views, cognition is best understood as emerging from a dynamic interaction of agent and 
environment, often over developmental time. However, there are variations among authors about what exactly these positions are and what they imply. For example, according to the extended mind thesis, mental states, including belief, are not merely in the head; rather they are environmentally extended (Clark, 2008; Clark \& Chalmers, 1998). Clark and Chalmers present what Clark (2008) calls the Parity Principle: "If, as we confront some task, a part of the world functions as a process which, were it done in the head, we would have no hesitation in recognizing as part of the cognitive process, then that part of the world is (so we claim) part of the cognitive process" (Clark \& Chalmers, 1998, p. 8). The enactive approach to the mind also endorses the thesis that our minds are not just in our brains and cannot be understood without our bodily actions and the environment in which we act (Thompson, 2007; Varela et al., 1991;). However, it differs from the extended mind thesis in that it holds that beliefs are not in the world, but emerge out of the complex interaction of the environment and the body. In addition, the two views differ in their understanding of the relationship between emotion and cognition: extended mind theorists keep them separate while the proponents of the enactive approach conceptualize them as internally related (Thompson \& Stapleton, 2008). They diverge in their understanding in the function of body and the very concept of embodiment: while extended mind theorists hold that body plays a functional role in cognition (as long as it works on the same problem-solving process as the brain and the environment), the enactive approach proponents endorse the thesis that the role of the body is basic in the interaction between organism and the environment. Through such interaction the process of cognition is created. We will come back to and elaborate this point shortly. 
However, the main point of difference, as it pertains to the nature of belief is their stand on the nature of representationalism, the view that we need to represent the world internally in order to act intelligently. Andy Clark, who is one of the main proponents of the extended mind thesis, argues for the possibility of redefining the concept of representation so that it becomes useful in our accounts of extended cognitive processes (Clark, 2001). On standard accounts representations are context-independent and formed independently from our bodily actions, our environment, or our interests at that particular moment. Clark suggests that we could redefine the notion of representation in such a way as to make it context-dependent where environment, our interests and goals, as well as our body become relevant for the formation of representations. For him, this path should be left open at least until empirical evidence supporting non-representational accounts of higher cognitive processes accumulates.

According to the 'radical embodied cognition thesis' (as Clark (2001) calls it) and 'enactive approach' (Thompson, 2007; Varela et al. 1991) we should study all cognitive processes in terms of complex, non-linear dynamic systems. For Thompson, organisms do not process information. Nor do they form context-independent representations in a computational sense. (They do not form context-dependant representations for that matter either). Instead, they 'create meaning' which is always relative to the particular situation. Creation of meaning starts happening even on the level of unicellular organisms. Such organisms are self-maintaining systems that select important from unimportant molecules in their environment (i.e. molecules that are relevant for their survival and those that are not). Thus, the relevant molecules get value and have special status for the organism. Here, on the level of unicellular organisms, we can find precursors of meaning and values 
that humans create in their cultural environment. It is important to note that in the same way that we do not need to invoke representations to account for the behavior of such organisms we do not need to invoke representations to account for human behavior.

Applied to the case of Fido, we can say that Fido does not need to internally process information about the bone or form a representation of the bone in order to act intelligently (i.e. to find it when needed). The buried bone has particular meaning for him, just as sucrose has particular meaning for E. Coli. The bone, and the sucrose, both stand out from the rest of the environment because they have direct connection to the needs of the organisms. And, radically, from this it follows that both unicellular organisms such as E. Coli and complex organisms such as Fido have minds and form beliefs about sucrose and bones respectively. Specifically, for the enactive approach, cognition is the 'know-how' in a particular situation and is performed through embodied action (finding the bone or getting to sucrose). Cognition defined in this way is 'sensemaking' or meaning creating, and as such emerges in the ongoing interaction between the organism and the environment. This implies that cognition is the property of all living organisms including unicellular ones. So, again if we ask whether E. Coli has a belief about where the sucrose is the answer should be yes. Belief in this case would be tied to creation of meaning and the ongoing cognitive process.

It could be argued that the enactive view of mind and cognition is nothing but watering down what we mean by these terms to the point that they lose their meaning altogether. In other words, if we now need to endorse the claim that E. Coli has beliefs along with maple trees, gold fish, caterpillars, iguanas, birds, monkeys, orangutans, and humans the question is whether we, by endorsing such a claim, lose the tool for making 
important distinction between these organisms, their cognitive capacities, and complexity of their behaviors. However, this does not need to be the case. While the enactive approach to cognition does establish the continuity of cognition across the living world, this does not imply that there are no differences between simpler and more complex organisms. It's just that the way to determine the differences becomes more complicated. So, instead of identifying certain cognitive capacities such as language, theory of mind, the ability to form representations and the like as the key points of categorical difference between humans and lower animals, one needs to take a closer look at the level of complexity of interactions between organisms and their environments. Organisms of different complexity establish different interactions with their environment. In this way they do form or create meaning differently, which is important for how cognitively advanced they are, and accordingly how complex their beliefs are. Multicellular organisms with neural systems are expected to have complex interactions with the environment (environment for such organism could be natural, social and cultural as is the case with humans) while unicellular, less structured organisms are expected to exhibit simple forms of interactions. Thus, beliefs along with cognitive processes of simpler organisms do not have the kind of powers that we see in more complex organisms, such as humans who use language. For example, E. Coli could not engage in prediction outside its very limited domain, nor could it engage in inference-making. Nonetheless, its cognitive powers serve its function to get the sucrose it needs.

This leads to the main implication of the enactive approach for the way we should investigate MCC: If we are to track differences in mental capacities between humans, animals and even plants we need to study interactions between organisms in their own 
environments before thinking about controlled experiments confined to the laboratory setting, insofar as such a setting does not model the natural environment of the organism under investigation (see also Chapter 25 this volume).

\section{Methodological Implications of Non-Representational Belief $(h 1)$}

We have argued that the MCC is not undermined by language when it comes to the question of animal belief, for two reasons: there exist methods for determining animal belief content, and, given both the possibility of non-representational accounts of belief and the cartographical models of representations, there is no special worry about the representational vehicle of thought without language. In addition, if the antirepresentationalists are correct, there is no categorical definition of belief, that is, no definition that would tie belief to language, concepts, content, or representations. Rather, "belief" is a cluster term that includes dispositional stereotypes and patterns of behavioral and affective responses that can be analyzed only in terms of an interaction between the organism and the environment. Further, belief is not binary; there are degrees of belief, and there is belief relative to a context.

Because the default assumption in comparative cognition research has been representationalism, we think it is worthwhile to explore how this assumption has shaped the research, and how a non-representationalist view of belief might suggest different ways we should study whether animals have beliefs, what sorts of beliefs they have, and whether they can attribute beliefs to others. For a non-representationalist about belief, in order to study the belief of an organism we need to look carefully at the way that organism behaves in its own environment and the kind of patterns of behavior it 
establishes in relation to the physical and social triggers of its environment. By using ethological methods we can study natural behavior, and by conducting experiments within that environment, as some do, we can uncover species' typical patterns of behavior. When comparing different species we will see more or less complex patterns of behavior, but we won't be able to say definitively that one species has beliefs and the other does not; for the non-representationalist there is no natural dividing line between organisms who believe and those who do not believe, there are only degrees of complexity. By uncovering the various patterns of response, we can come to understand how best to characterize the beliefs of various species, and only then can we examine whether members of that species likewise characterize the patterns of their conspecifics. If an anti-representational view of belief is correct, then research that does not begin with an understanding of species-typical patterns of response to ecologically valid environmental stimuli will likely fail to uncover the actual capacities of members of that species.

One area in which the assumption of representationalism has played an important role is in the theory of mind research program. We conclude with a discussion of this research program, and the impact non-representationalism should have on future research in this area.

\section{Theory of mind research $(h 2)$}

Ever since the publication of David Premack and Guy Woodruff's study on chimpanzee theory of mind (1978), the focus of theory of mind research has been on whether the chimpanzee (or other species) understands false belief. The reason for the 
focus on false belief stems from the suggestions made independently by three philosophers commenting on the study. Following the current trend in philosophy, Jonathan Bennett (1978), Daniel Dennett (1978), and Gilbert Harman (1978) suggested that for a chimpanzee to know that others have beliefs, he has to know that beliefs can be false. In order to determine whether chimpanzees have this knowledge, experimenters should present the chimpanzee with a problem that would force him to alter his own behavior in expectation of another's behavior when that behavior stems from a belief the chimpanzee knows to be false. To illustrate, Dennett suggested that a good test of theory of mind will rest on a coordination problem that involves the subject responding to the actor's false belief. This should ensure that the anticipated action be relatively novel, and that an associationist explanation is not possible. Dennett suggested modeling a test after a Punch and Judy puppet show. Children watching Punch and Judy squeal for joy when Punch is about to push a box over a cliff, because though Punch thinks that Judy is still in the box, the children know that Judy snuck out when Punch wasn't looking.

Dennett suggested constructing a similar situation for chimpanzees: First let the chimpanzee observe someone move the banana from one box to another. Then when the experimenter comes to retrieve the banana, the chimpanzee who has a theory of mind will predict that the experimenter will go to the wrong box. The only problem, as Dennett noted, is how to tease out the chimpanzee's expectation. In any case, the task requires that the subject understand that the actor has a false belief, and thus will act against his own (or the chimpanzee's) interests.

These suggestions for testing chimpanzee theory of mind were taken up by developmental psychologists, first with Wimmer and Perner's (1983) false belief task, 
and later with other tests of false belief such as the unexpected contents task (Gopnik \& Astington, 1988). Though initially there was little published about animal theory of mind, in the last ten years there has been a resurgence of interest in primate theory of mind with the development of ecologically sensitive competitive studies modeled after the false belief task (Hare et al., 2000, 2001; Santos et al., 2006). These studies, and discussion of animal theory of mind, continue within the theoretical framework laid out in commentary on the 1978 study. For example, David Premack sees understanding false belief as a methodological criterion: "False belief is pivotal to the claim that an individual is attributing states of mind" (Premack \& Premack, 2003, p. 148).

These false belief experiments assume the representation theory of mind. The focus of the false belief studies have been on the property of semantic evaluability. However, this focus is wrongheaded if the key features of belief are patterns of response in triggering conditions. Though the current generation of research on ape theory of mind is sensitive to the first condition for studying belief in animals, namely understanding species-typical patterns of response to ecologically valid environmental stimuli, it is still firmly in the grips of the representationalist theoretical construct.

We suggest that non-representational belief and theory of mind be studied in other species by taking a page from the personality trait research program, which attempts to uncover patterns of behavior by extracting expert knowledge from caregivers and others with know-how about the species. Species including orangutans, chimpanzees, cats, dogs, octopi and guppies have been shown to have individual differences and personality traits that have been analyzed by use of species-relative versions of the Five-Factor Model (FFM) of human personality (Gosling \& John, 1999), and cats and dogs have 
shown individual behavioral differences on the individual circumplex model of personality (Zeigler-Hill \& Highfill, 2010). The human FFM was developed to describe the way attributions of trait terms group together into statistically significant clusters, and it organizes personality into five domains: Neuroticism, Extraversion, Openness to Experience, Agreeableness, and Conscientiousness. It has been argued that the human FFM accommodates most individual differences (Digman, 1990) and that there are underlying genetic factors related to the identified traits (Bouchard \& Loehlin, 2001 have a review).

In the study of animal personality traits, researchers have typically focused on captive animals in zoo or aquaria exhibits, rather than research subjects or wild animals, and they ask caregivers to rate an individual using the same methods used in developing the human FFM. King and Figueredo (1997) and Weiss, King, \& Perkins (2006) used this method to assess personality in chimpanzees and orangutans, respectively. As with the development and implementation of the FFM, raters are given lists of adjectives and asked to rate an animal on a 7-point Likert scale. Raters' judgments are assessed for statistical reliability both within and between raters, and the results indicate both differences and similarities between human, chimpanzee, and orangutan personality factors.

If non-representationalism about belief were correct, then a theory of mind would just be something like the ability to attribute unique sets of behavioral dispositions and emotional responses to others given particular situations. On this assumption, to study theory of mind in chimpanzees, researchers could rely on the personality research as a starting point. However, given the role of the environment in the triggering or 
constitutive aspects of belief, extracting expert knowledge of chimpanzee beliefs would be better done with experts who work with the animals in a natural setting, rather than those working with captive animals. Once there is a baseline for the sorts of beliefs that the chimpanzees have one can begin to investigate whether those patterns of response are salient to other chimpanzees. While there has been little formal study of chimpanzee “theory of personality", it appears that chimpanzees can recognize some personality attributes such as selfish and generous (Subiaul et al. 2008). As well, there are some suggestive reports that animals recognize individual differences in patterns of behavior, such as norm violators, and treat such individuals differently (Bekoff \& Pierce, 2009; deWaal, 2006). Sensitivity to others' patterns of behavioral and phenomenal response in particular contexts could be sufficient for having a theory of mind on a nonrepresentational understanding of belief.

\section{Conclusion $(h 1)$}

The MCC, while not a premise that follows from materialism and evolutionary theory, is an empirical hypothesis that can be investigated within the field of evolutionary comparative cognition. But in order to investigate the claim, it must be clarified. We have seen that mind is an umbrella term, and the truth of the MCC can only be examined in its instances; researchers can examine aspects of mind: personality, consciousness, emotion, memory, reasoning, categorization, knowledge development, belief, theory of mind. However, we should be careful not to think that these elements are intrinsically separable. Rather, given how poorly we currently understand the nature of mind, even 
when it comes to humans, we should not expect that these starting theoretical concepts are going to carve nature at its joints. Instead, for example, we may find that emotion is inextricably tied with rationality, as researchers across disciplines have argued (Damasio, 1994; Haidt, 2001; Lewis, 2005; Thompson, 2007).

When examining the continuity claim when it comes to belief, and the ability to attribute belief, we should be cautious about the theoretical commitments assumed by one's research program. Evolutionary comparative psychology can contribute to our understanding of the nature of such mental features by devising experiments from different theoretical frameworks in order to help show the empirical adequacy of the theory.

We think there is good reason to examine theory of mind from within the framework of dispositionalism about belief, and its kinship with embedded, situated, and enactive approaches to mind. This approach has been fruitful in artificial intelligence and robotics, and given the formative or constitutive role the environment has for cognition in such views, the approaches marry nicely with an evolutionary approach to comparative cognition (Barrett \& Henzi, 2005). The above approaches also suggest a return to classical ethology as a starting point for studying theory of mind in other species. Studying human cognition is relatively easy, since researchers are born into the relevant field and spend their lives learning the patterns of other humans. In order to develop the same degree of understanding of another species - an understanding that can serve as a foundation for controlled experimentation - a similar embedding into the natural lives of that species is warranted. 


\section{Future Directions (h2)}

1. We can develop research programs that investigate the same cognitive process from a number of different theoretical perspectives.

2. In order to study cognition from the perspective of embodied, enactive and dispositional approaches to belief and cognition, we must examine behavior in the animal's natural environment.

3. Because we may be able to gain evidence for different theories of mental features by examining naturalistic animal behavior, it is useful to study cognition in both natural and laboratory settings.

4. In order to facilitate field research on cognition, we should develop guidelines, a handbook, or a textbook that focuses on methods used to study cognition in the field in order to train new generations of researchers. 


\section{References}

Allen, C. (1999). Animal concepts revisited: The use of self-monitoring as an empirical approach. Erkenntnis, 51, 537-544.

Anderson, L. (1976). Charles Bonnet's taxonomy and chain of being. Journal of the History of Ideas, 37, 45-58.

Armstrong, D. (1973). Belief, truth and knowledge. Cambridge, MA: Cambridge University Press.

Baillargeon, R., \& DeVos, J. (1991). Object permanence in young infants: Further evidence. Child Development, 62, 1227-1246.

Barrett, L., \& Henzi, P. (2005). The social nature of primate cognition. Proceedings of the Royal Society B: Biological Sciences, 272, 1865-1875.

Bekoff, M., \& Pierce, J. (2009). Wild justice: The moral lives of animals. Chicago, IL: University of Chicago Press.

Bennett, J. (1978). Some remarks about concepts. Behavioral and Brain Sciences, 1, 557-560.

Bermudez, J. (2003). Thinking without words. Cambridge, MA: MIT Press.

Braddon-Mitchell, D. \& Jackson, F. (1996). The philosophy of mind and cognition. Oxford, Oxford University Press.

Brooks, R. (1991). Intelligence without representation. Artificial Intelligence, 47, 139-159.

Bouchard, T. J. J., \& Loehlin, J.C. (2001). Genes, evolution, and personality. Behavior Genetics, 31, 243-273.

Buss, L.W. (1987). The evolution of individuality. Princeton, NJ: Princeton University Press.

Camp, E. (2007). Thinking with maps. Philosophical Perspectives, 21, 145-182. 
Chomsky, N. (1959). A review of B.F. Skinner's "Verbal Behaviour". Language, 35, 2658.

Chomsky, N. (1968). Language and mind. New York, NY: Harcourt Brace Jovanovich.

Chomsky, N. (1980). Human language and other semiotic systems. In T. A. Sebeok and J. Umiker-Sebeok (Eds.), Speaking of apes: A critical anthology of two-way communication with man (pp. 429-440). New York, NY: Plenum Press.

Churchland, P. M. (1981). Eliminative materialism and the propositional attitudes. The Journal of Philosophy, 78, 67-90.

Clark, A., \& Toribio, J. (1994). Doing without representing. Synthese, 101, 401-431.

Clark, A., \& Chalmers, D. (1998). The extended mind. Analysis, 58, 7-19.

Clark, A. (2001). Mindware: An introduction to the philosophy of cognitive science. New York, NY: Oxford University Press.

Clark, A. (2008). Supersizing the mind. New York, NY: Oxford University Press.

Cummins, R. (1996). Representations, targets, and attitudes. Cambridge, MA: MIT Press.

Damasio, A. (1994). Descartes' error: Emotion, reason, and the human brain. New York, NY: GP Putnam's Sons.

Darwin, C. (1859/2003) On the Origin of Species. New York: Signet Classics.

Darwin, C. (1871/2010). The descent of man. Mineola, New York, Dover.

Davidson, D. (1982). Rational animals. Dialectica, 36, 317-327.

Davidson, D. (1984). Inquiries into truth and interpretation. Oxford, Oxford University Press.

Dennett, D. (1996). Kinds of Minds: Towards an Understanding of Consciousness. New York, NY: Basic Books.

Dennett, D. (1991). Real patterns. The Journal of Philosophy, 88, 27-51. 
Dennett, D. C. (1978). Beliefs about beliefs. Behavioral and Brain Sciences, 4, 568-570.

Descartes, R. (1637/2000). Discourse on the method. In R. Ariew (Eds.), René Descartes: Philosophical essays and correspondence (pp. 72). Indianapolis, IN: Hackett Publishing Company.

Digman, J. M. (1990). Personality structure: Emergence of the five-factor model. Annual Review of Psychology, 41, 417-440.

Dretske, F. (1988). Explaining behavior. Cambridge, MA: MIT Press.

Fodor, J. (1987). Psychosemantics. Cambridge, MA: MIT Press.

Fodor, J. (1975). The language of thought. New York, NY: Thomas Y. Crowell.

Frankel, J. (1989). Pattern formation: Ciliate studies and models. Oxford: Oxford University Press.

Gómez, J.-C. (2005). Species comparative studies and cognitive development. Trends in Cognitive Sciences, 9, 118-125.

Gopnik, A. and J. W. Astington (1988). Children's understanding of representational change and its relation to the understanding of false belief and the appearance-reality distinction. Child Development, 59, 26-37.

Gosling, S. D., \& John, O. P. (1999). Personality dimensions in non-human animals: A crossspecies review. Current directions in psychological science, 8, 69-75.

Haidt, J. (2001). The emotional dog and its rational tail. Psychological Review, 108, 814-834.

Hare, B., Call, J., Agnetta, B., \& Tomasello, M. (2000). Chimpanzees know what conspecifics do and do not see. Animal Behaviour, 59, 771-785.

Hare, B., Call, J., \& Tomasello, M. (2001). Do chimpanzees know what conspecifics know? Animal Behaviour, 61, 139-151. 
Harman, G. (1978). Studying the chimpanzees' theory of mind. Behavioral and Brain Sciences, $1,576-577$.

Hauser, M. (2000). Wild minds. New York, NY: Henry Holt.

Hauser, M.D., MacNeilage, P., \& Ware, M. (1996). Numerical representations in primates. Proceeding of the National Academy of the Sciences, 93, 1514-1517.

Hauser, M., \& Carey, S. (1998). Building a cognitive creature from a set of primitives: Evolutionary and developmental insights. In D. Cummins \& C. Allen (Eds.), The Evolution of Mind (pp. 51-106). New York, NY: Oxford University Press.

Hume, D. (1739-40/1978). A treatise of human nature. Oxford, Oxford University Press.

Hutto, D. D. (2008). Folk psychological narratives: The sociocultural basis of understanding reasons. Cambridge, MA: MIT Press.

Kant, I. (1798/1977). Anthropologie in pragmatischer Hinsicht (translated as Anthropology form a pragmatic point of view by Victor Lyle Dowdell). Carmbondale Southern Illinois Press.

King, J., \& Figueredo, A. J. (1997). The five-factor model plus dominance in chimpanzee personality. Journal of Research in Personality, 31, 257-271.

Korsgaard, C. (1996). Sources of normativity. Cambridge, MA: Cambridge University Press.

Lazareva, O. F., \& Wasserman, E. A. (2008). Categories and concepts in animals. In R. Menzel (Ed.), Learning Theory and Behavior (Vol. 1, pp. 197-226).

Lewis, D. (1994). Lewis, David: Reduction of Mind. In S. Guttenplan (Eds.), A Companion to the Philosophy of Mind (pp. 412-431). Oxford: Blackwell.

Lewis, M. (2005). Bridging emotion theory and neurobiology through dynamic systems modeling. Behavioral and Brain Sciences, 28, 169-194. 
Lovejoy, A. O. (1936/2009). The Great Chain of Being: The Study of the History of an Idea. New Brunswick, New Jersey: Transaction Publishers.

Marcus, R. B. (1990). Some revisionary proposals about belief and believing. Philosophy and Phenomenological Research, 50, 133-153.

Millikan, R. G. (1984). Language, thought, and other biological categories. Cambridge, MA: MIT Press.

Millikan, R. G. (1986). Thoughts without laws: Cognitive science with content. The Philosophical Review, 95, 47-80.

Oyama, S. (2000). The ontogeny of information: Developmental systems and evolution. Duke University Press

Oyama, S. (2001). What do you do when all the good words are taken? In S. Oyama, P.E. Griffiths, \& R.D. Gray (Eds.), Cycles of Contingency:Developmental Systems and Evolution, (pp. 177-195). Cambridge, MA: Massachusetts Institute of Technology.

Penn, D. C., Holyoak, K. J., \& Povinelli, D. J. (2008). Darwin's mistake: Explaining the discontinuity between human and nonhuman minds. Behavioral and Brain Sciences, 31, 109-178.

Pepperberg, I. M. (1999). The Alex studies: Cognitive and communicative abilities of grey parrots. Cambridge, MA: Harvard University Press.

Pinker, S. (1994). The language instinct. New York, NY: William Morrow and Company, Inc.

Pinker, S., \& Bloom P. (1990). Natural language and natural selection. Behavioral and Brain Sciences, 13, 707-784.

Premack, D., \& Woodruff, G. (1978). Does the chimpanzee have a theory of mind? Behavioral and Brain Sciences, 1, 515-526. 
Povinelli, D.J., \& Bering J.M. (2002). The mentality of apes revisited. Current Directions in Psychological Science, 11, 115-119.

Povinelli, D. J., \& Vonk, J. (2004). We don't need a microscope to explore the chimpanzee's mind. Mind and Language, 19, 1-28.

Premack, D., \& Premack, A. (2003). Original intelligence: Unlocking the mystery of who we are. New York, NY: McGraw-Hill.

Rescorla, M. (2009). Cognitive maps and the language of thought. British Journal for the Philosophy of Science, 60, 377-407.

Santos, L. R., Nissen, A. G., \& Ferrugia, J. A. (2006). Rhesus monkeys, Macaca mulatta, know what others can and cannot hear. Animal Behaviour, 71, 1175-1181.

Schwitzgebel, E. (2002). A phenomenal, dispositional account of belief. Nous, 36, 249-275.

Schwitzgebel, E. (2001). In-between believing. The Philosophical Quarterly, 51, 76-82.

Speaks, Jeff, "Theories of Meaning", The Stanford Encyclopedia of Philosophy (Summer 2010 Edition), Edward N. Zalta (ed.), URL= $<$ http://plato.stanford.edu/archives/sum2010/entries/meaning/>.

Spelke, E. S. (1991). Physical knowledge in infancey: Reflections of Piaget's theory. In S. Carey \& R. Gelman (Eds.), Epigenesis of Mind: Studies in Biology and Cognition. Hillsdale, NJ: Erlbaum.

Sterelny, K., \& Griffiths, P.E. (1999). Sex and death: An introduction to the philosophy of biology. Chicago, IL: University of Chicago Press.

Stich, S. P. (1979). Do animals have beliefs? Australasian Journal of Philosophy, 57, 15-28.

Stich, S. (1983). From folk psychology to cognitive science: The case against belief. Cambridge, MA: MIT Press. 
Subiaul, F., Vonk, J., Okamoto-Barth, S., \& Barth, J. (2008). Chimpanzees learn the reputation of strangers by observation. Animal Cognition, 11, 611-623.

Thelen, E., \& Smith, L. (1994). A dynamic systems approach to the development of cognition and action. Cambridge, MA: MIT Press.

Thompson, E. (2007). Mind in life: Biology, phenomenology, and the sciences of mind. Cambridge, MA: Belknap Press of Harvard University Press.

Thompson, E., \& Stapleton, M. (2009). Making sense of sense-making: Reflections on enactive and extended mind theories. Topoi, 28, 23-30.

Tomasello, M. (1999). The Cultural Origins of Human Cognition. Cambridge, MA: Harvard University.

Uller, C. (1997). Origins of Numerical Concepts: A Comparative Study of Human Infants and Nonhuman Primates. Cambridge, MA: MIT Press.

Van Gelder, T. (1995). What might cognition be, if not computation? The Journal of Philosophy, 92, 345-381.

Vonk, J., \& Povinelli, D. J. (2006). Similarity and difference in the conceptual systems of primates: The unobservability hypothesis. In E. Wasserman \& T. Zentall (Eds.), Comparative Cognition: Experimental Explorations of Animal Intelligence (pp. 363-387). New York: Oxford University Press.

de Waal, F. (2006). Primates and philosophers: How morality evolved. Princeton, NJ: Princeton University Press.

Weinert, F. (2009). Copernicus, Darwin, and Freud: Revolutions in the history and philosophy of science. Oxford: Wiley-Blackwell. 
Weiss, A., King, J., \& Perkins, L. (2006). Personality and subjective well-being in orangutans (Pongo pygmaeus and Pongo abelii). Journal of Personality and Social Psychology, 90, 501-511.

Wimmer, H. J., \& J. Perner (1983). Beliefs about beliefs: Representation and constraining function of wrong beliefs in young children's understanding of deception. Cognition, 13, 103-128. 